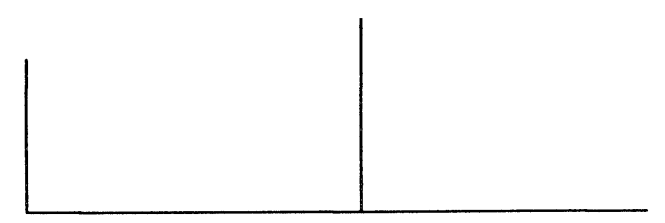

Rev. Latinoam. Psicopat. Fund., IX, 4, 676-681

\title{
Comissão de consultores dos EUA revisa regras para pesquisa nas prisões*
}

Mônica Teixeira

O governo dos Estados Unidos vai modificar as normas que regulam a participação de prisioneiros em experimentos científicos. Em julho, o Instituto de Medicina da Academia Nacional de Ciências divulgou um relatório sobre o assunto, realizado por um grupo de especialistas, a pedido do Escritório de Proteções para a Pesquisa com Humanos, do Departamento de Saúde (equivalente ao Ministério da Saúde) dos EUA. Intitulado "Considerações Éticas para a Pesquisa envolvendo Prisioneiros", o relatório, por um lado, recomenda que uma diversidade maior de experimentos possa ser realizada com prisioneiros; por outro, propõe um controle mais estrito sobre eles, ao exigir seu acompanhamento independentemente da fonte financiadora - hoje, apenas experimentos financiados por certas agências federais são monitoradas.

Até o início dos anos 1970, cerca de $90 \%$ de todos os produtos farmacêuticos comercializados nos EUA haviam sido testados em prisioneiros - como conta o texto da revista Lancet que "Observando a Medicina" selecionou para publicar nesta edição. A revelação da forma pela qual detentos da Prisão de Holmesburg, em Filadélfia, foram usados para testar desde produtos dermatológicos até alucinógenos levou ao surgimento da regulamentação atual. $\mathrm{O}$ caso

* Artigo publicado em The Lancet, v. 368, n. 9542, 30 September 2006. 


\section{OBSERVANDO}

A MEDICINA

ano IX, n. 4, dez/2006

da prisão de Holmesburg se combinou a outro: em 1972, um repórter da Associated Press descobriu e publicou que médicos a serviço do governo federal mantiveram sem tratamento 400 homens com sífilis, na comunidade de Tuskegee, no Alabama. O "experimento" durou 40 anos, chamava-se "Estudo de Tuskegee sobre sífilis não tratada no homem negro" e seu objetivo era o de observar as conseqüências do progresso da doença sobre o corpo humano. O fato de tratamento haver surgido para a doença não foi informado aos homens do Alabama, nem provocou mudança na conduta dos "experimentadores". Juntos, o caso da prisão de Holmesburg e o da comunidade de Tuskegee ensejaram a formulação das regras que hoje protegem quem participa de experimentos biomédicos ou "de comportamento", para usar a expressão de um dos comitês que revisaram o assunto nos anos 1970. Especialmente, esses comitês enfatizaram a centralidade do "livre poder de escolha" sobre participar ou não dos experimentos como condição para o engajamento neles; e é esse o ponto delicado quando se trata da participação de presos.

"O sistema correcional dos EUA é diferente hoje do que era nos 1970s", informa em sua primeira linha o sumário do relatório do Instituto de Medicina. Uma das mudanças, apontada logo no segundo parágrafo, é o fato de a população ter quadruplicado: há, atualmente, 7 milhões de pessoas nas cadeias, penitenciárias, com sentença suspensa ou em liberdade condicional. Quem acompanha as dificuldades atuais da indústria farmacêutica no recrutamento de voluntários para participar de ensaios clínicos (como mostrado por esta seção desde seu aparecimento), imagina logo o quanto seria vantajoso a ela poder engajar mais presidiários neles. Ao jornal New York Times, um porta voz esclareceu que os laboratórios não se imiscuíram nos trabalhos do novo relatório.

É possível que não mesmo - o setor vem sofrendo revezes perante a opinião pública e manter-se afastado de uma mudança na regulamentação sobre recrutamento de presos para testes clínicos é prudente. Mas um exemplo da força da atração que a população encarcerada pode exercer sobre quem conduz esse tipo de experimentos foi relatado por Allen M. Hornblum, professor da Temple University, no livro que publicou em 1998 sobre os acontecimentos na prisão de Holmesburg. A iniciativa de estabelecer lá dentro um centro de pesquisas clínicas partiu do dermatologista Albert Kligman, da Universidade da Pensilvânia. De acordo com o relato de Hornblum, o Philadelphia Bulletin, em 1966, registrou o pensamento do médico ao visitar Holmesburg pela primeira vez: "Tudo o que enxerguei à minha frente foram acres de pele - como se eu fosse um fazendeiro que, pela primeira vez, visse campos de terras férteis".

$\mathrm{O}$ artigo da revista The Lancet noticiando a próxima mudança de regulamentação nos EUA foi publicado no dia 30 de setembro e escrito por Samuel Loewenberg. A seleção, tradução e esta introdução são de Mônica Teixeira. 


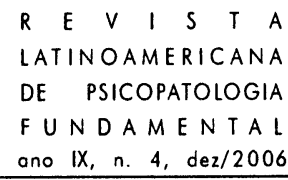

Comissão de consultores dos EUA revisa regras para pesquisa nas prisões

Lembranças constrangedoras do abuso disseminado de prisioneiros dos EUA engajados em ensaios clínicos de drogas e cosméticos reviveram desde agosto - quando uma comissão consultiva do governo publicou um relatório que pode levar à ampliação da permissão para sua realização entre as 7 milhões de pessoas no sistema penal norte-americano.

Experimentos com novas drogas, produtos químicos e cosméticos que usem prisioneiros são quase completamente proibidos pela legislação atual. As restrições resultaram de revelações feitas há trinta anos, sobre abusos sistemáticos e terríveis ocorridos no sistema correcional, algumas vezes envolvendo grandes universidades de pesquisa. Um editorial recente do New York Times citou práticas "medievais", nas quais presos foram submetidos a "procedimentos experimentais perigosos e não éticos".

Em um caso notório, envolvendo a Escola de Medicina da Universidade da Pensilvânia, detentos da Prisão de Holmesburg, na Filadélfia, foram expostos a produtos radioativos, carcinogênicos e a alucinógenos sem que tenham sido informados dos riscos. A lista de patrocinadores dos testes incluía grandes companhias farmacêuticas e agências do governo. Depois do escândalo, revelouse que experimentos similares aconteceram em outras prisões.

Até o início dos anos 1970, quando as proibições foram estabelecidas, aproximadamente $90 \%$ das novas drogas haviam sido testadas em prisioneiros. Desde então, pesquisadores têm reclamado da grande escassez de voluntários. Prisioneiros são uma população de fácil acesso e fácil acompanhamento - e para algumas pessoas isto significa que eles são uma fonte potencialmente valiosa de participantes de ensaios clínicos.

A proposta de revisão do regime de testes nas prisões, preparada pela comissão consultiva do Instituto de Medicina, foi desenhada para evitar os abusos que ocorreram nos experimentos de pesquisa do passado. Defensores dos prisioneiros e médicos especialistas em ética, no entanto, ainda estão preocupados com a possibilidade de mau tratamento e exploração dessas populações vulneráveis.

Mesmo agora, notou a comissão do Instituto de Medicina, as regras só valem para uma pequena parte da população total do sistema penitenciário muitos experimentos podem estar acontecendo sem o conhecimento público.

Os que propõem a ampliação dos ensaios clínicos dentro das prisões argumentam que, com salvaguardas apropriadas, eles podem ao mesmo tempo beneficiar o público e dar a presos em sofrimento acesso a tratamento médico de alta qualidade. 


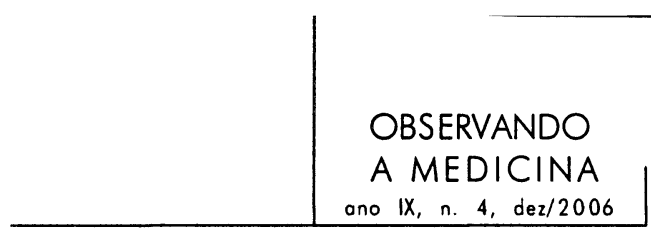

Pessoas com HIV/AIDS e outras doenças debilitantes freqüentemente competem para engajar-se em testes de drogas, lembra Lawrence Gostin, o presidente da comissão consultiva e professor de direito e saúde pública na Universidade de Georgetown. "Penso que não há justificativa para excluir detentos sistematicamente de ensaios clínicos que podem beneficiá-los", diz. No entanto, ele adverte, "o risco de abuso ético é muito mais alto" nas prisões do que em situações normais.

O ímpeto de revisar a regulamentação atual surgiu depois de reclamações de que as regras de hoje não são claras, de acordo com Bernard Schwetz, do Departamento de Saúde, onde dirige o escritório responsável pela proteção de quem participa de pesquisas.

Schwetz assegura que as preocupações éticas especiais suscitadas pelos detentos obrigam seu departamento a proceder de forma especialmente cuidadosa. "Não é nossa intenção facilitar a pesquisa com esta população vulnerável", diz. "Não se deve usar prisioneiros para pesquisa apenas porque eles são fáceis de encontrar".

As regras propostas pela comissão consultiva incluem salvaguardas. Somente as fases finais de ensaios clínicos seriam permitidas, depois de os novos compostos terem passados pelas fases de testes 1 e 2 , que verificam sua segurança e efetividade. Além disso, ensaios clínicos só podem incluir populações encarceradas se elas representarem não mais que metade do total de participantes. $O$ relatório sugere permitir a detentos correr maiores riscos do que os permitidos atualmente porque eles poderiam também receber maiores benefícios.

A revisão proposta pela comissão não obriga o governo a efetuar mudanças e será considerada pelo Departamento de Saúde durante o mês de novembro.

$O$ relatório do Instituto de Medicina também recomenda um alargamento da definição sobre quem é coberto pelas regras de ensaios clínicos para prisões. Atualmente, elas incluem cerca de dois milhões de adultos nas cadeias e penitenciárias. A expansão proposta estenderia a cobertura para outras cinco milhões de pessoas em condicional ou com sentenças suspensas. Os autores do relatório argumentam que esta população, embora não esteja mais atrás das grades, permanece particularmente vulnerável de exploração por estar sujeita à vontade do Estado.

Uma das maiores falhas do sistema atual, de acordo com Gostin, é que ele somente cobre a pesquisa financiada pelo Departamento de Saúde, pela Administração da Seguridade Social, e pela Agência Central de Inteligência. Pesquisa financiada por outros organismos está isenta de supervisão, significando que não há registro público acessível sobre elas. No momento, apenas "uma muito pequena porcentagem" da pesquisa com seres humanos nas prisões recebe supervisão, diz Gostin. Não há um sistema em funcionamento para acompanhar 


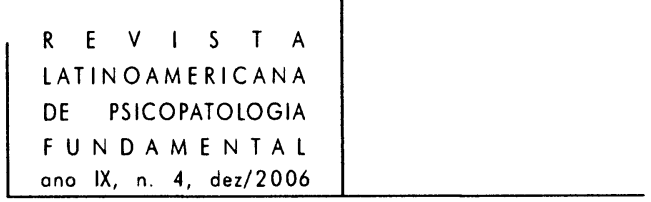

e monitorar os projetos de pesquisa; e esforços feitos pela comissão para chegar a uma lista abrangente terminaram em fracasso. "Ninguém sabe" quanta pesquisa biomédica está sendo feita no momento nas prisões, relata Gostin.

A Universidade da Pensilvânia, por exemplo, conduz atualmente cerca de trinta estudos com prisioneiros, de acordo com o jornal Philadelphia Inquirer. Pelo fato de a maior parte deles não ser financiada pelo governo federal, o escritório responsável pela proteção de participantes de ensaios clínicos lista apenas duas.

Sob a nova regulamentação proposta, qualquer pesquisa usando detentos deverá ser supervisionada, independentemente da fonte de financiamento. $\mathrm{O}$ relatório também recomenda incluir instalações prisionais locais, estaduais e privadas e a criação de uma central de dados.

Mesmo com todas essas salvaguardas, permanece a questão de como estabelecer consentimento informado voluntário - um requisito básico para legitimar a pesquisa - entre pessoas encarceradas. Afinal, a liberdade dos prisioneiros está, por definição, estreitamente controlada. Alguns prisioneiros podem ser secretamente pressionados a participar dos ensaios; outros podem aceitar participar com a expectativa de vir a receber melhor tratamento ou serem libertados mais cedo. Além disso, muitos prisioneiros são analfabetos, o que coloca a questão sobre a capacidade deles de entender ou não a freqüentemente complicada linguagem legal dos formulários de consentimento.

Há também o problema do desespero. Com freqüência, as prisões americanas carecem severamente de recursos, estão superlotadas e tem mau atendimento médico. Doenças contagiosas se espalham. Como o relatório nota, o acesso a tratamento médico adequado é freqüentemente tão difícil que existe um perigo real de os prisioneiros se engajarem em um ensaio clínico simplesmente como "uma ação desesperada para obter tratamento".

O Estado da Califórnia, com as maiores e mais superlotadas prisões do país, já anunciou que não vai permitir o uso de seus prisioneiros em testes. Um porta-voz do escritório de supervisão do problemático sistema penitenciário do Estado afirmou que, nesse estágio, não há assistência médica básica para detentos, e que o Estado está ainda tentando providenciar instalações tão rudimentares quanto pias nas quais os médicos das prisões possam lavar as mãos.

\section{O escândalo da Prisão de Holmesburg}

Um dos mais notórios casos de exploração de detentos ocorreu na Prisão de Holmesburg, nos arredores de Filadélfia, entre 1950 e 1970. 


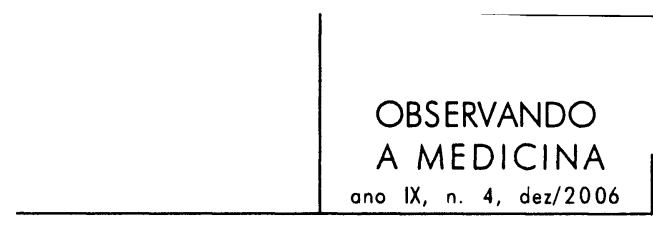

Cerca de trezentos detentos que passaram por ali processaram a Universidade da Pensilvânia, a Cidade da Filadélfia, a Dow Chemical e a Johnson \& Johnson, por terem sido submetidos a testes com materiais radioativos, dioxina e drogas alucinógenas. A ação nunca foi aceita pela Justiça por causa do tempo já decorrido, mas os detentos planejam apelar.

Os experimentos ocorreram entre 1951 e 1974, e incluíram várias agências federais e mais de trinta empresas. Bernard Ackerman, um dermatologista de Nova Iorque que participou dos experimentos como residente de segundo ano, diz não ter percebido inicialmente o significado do que os pesquisadores estavam fazendo. "À medida que o tempo passava, tornou-se claro para mim que aquilo era uma violação do Código de Nuremberg”, diz.

Ackerman lembra-se que os pesquisadores-chefes recebiam grandes somas das empresas químicas e farmacêuticas para testar produtos por meio do engajamento dos detentos em práticas que classifica de abusivas. "É surpreendente imaginar que um dermatologista usasse drogas radioativas ou psicotrópicas nos experimentos com prisioneiros", observa Ackerman.

A maior parte da pesquisa era inútil, afirma. Naquele tempo, uma companhia farmacêutica pagaria cerca de US\$ 25 mil por um estudo. Os detentos recebiam US $\$ 300$, e os pesquisadores e a Universidade ficavam com o resto. "Sob o disfarce de pesquisa, eles estavam conduzindo um grande negócio”.

Ackerman acrescenta que experimentos similares também foram conduzidos em estabelecimentos para crianças deficientes e idosos sob controle público. Em resposta a The Lancet, a Escola de Medicina da Universidade da Pensilvânia apresentou uma declaração. Nela, observa que, na época dos experimentos em Holmesburg, usar prisioneiros para pesquisa biomédica "era uma prática comumente aceita".

Sem admitir culpabilidade, a declaração continua: "A Universidade continua a convidar qualquer antigo prisioneiro que sinta ter sido prejudicado a longo prazo como resultado de estudos patrocinados por ela na Prisão de Holmesburg antes de 1973 a nos contatar para avaliação médica gratuita e tratamento subseqüente, caso seja apropriado". 